\title{
The major component of a large, intracellular proteinase accumulated by inhibitors is a complex of $\alpha_{2}$-macroglobulin and thrombin
}

\author{
A. Tsuji *, T. Arai, P.S. Furcinitti **, J.P. Langmore and K. Kurachi

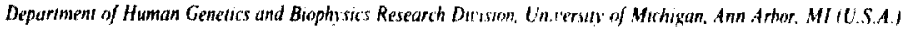

(R.cecibed 29 Norember 1991$)$

Key words: Leupeptin; findocytosis; Recepter

\begin{abstract}
A large, intracellular proteinase accumulated by inhibitors (PABI) was found in cultured mammulian cells as a largc. multicatalytic proteinase with a greatly elevated concentration in the presence of small peptide proteinawe inhibitors (Tsuji and Kurachi (1989) J. Biol. Chem. 264, 16093). Electron microscopic analysis showed that the tertiory structure of PABI highly resembled that of $\alpha_{2}$-macroglobulin complexed with a proteinase(s). Isolation of the anti-PAB] cross-reacting material from calf serum added to the culture media of baby hamster kidney cells further supported that the primary component of PABI was $\alpha_{2}$-macroglobulin. Immunoblot analyses and the substrate specificity of PABI indicated that the major proteinase component contained in PABl was thrombin. When $\alpha_{2}$-macrogloioulin waj duided to the PABI-depleted serum, a significant accumulation or a degradation of the intracellular $\alpha_{2}$-macroglobulin was observed in the presence or absence of kupeptin. respectively. Similarly, when thrombin was added to the PABI-depleted fetal calf serum supplemented with fresh $\alpha_{2}$-macroglobulin, a significant anutent of intraceilular thrombin was found only in the presence of leupeptin. These results indicate that the major component of the intracellular PABI molecules is a complex of $\alpha_{2}$-macroglobulin with thrombin which is internalized from the culture media. Intracellular accumulation of PABI, therefore, is a phenomenon primarily relevant to the culture cells. Whether or not PABI is also generated in certain physiological or pathological conditions requires further study.
\end{abstract}

\section{Introduction}

PABI is a large, multicatalytic intracellular proteinase of about $700 \mathrm{kDa}$ which was recently characterized [1]. When a small proteinase inhibitor. such as leupeptin, was added to the culture media of mammalian cells, the concentration of PABI increased 100 200-fold above the basal level. This unique accumulation was considered to be due to greatly reduced levels of degradation in the presence of such a protcinase inhibitor. PABI showed a rather complex substrate

\footnotetext{
* Present audress: Department of Biological Science and Technol. ogy. Faculty of Enginering, Universily of Tokushima, Tokushima Jap̣an.

* Present dddress: Departinent of Molecular Cellular and Developranual Biotogy, University of Colorado, Boukder, CO, U,S.A.
}

Correspondence: K. Kurachi, Department of Human Ciene lics, Bsiversity of Michigan, Ann Arbor, MI 48109, U.S.A. specificity. with obvious similarity to that of trypsin and chymotrypsin. but not to those of plasmin, elastase or cyteine proteinases. PABI was a multimer of a major subunit of $84 \mathrm{kDa}$ and was not activated by ATP. Thest properties were unique to PABI and clearly different from several other known, large protsinases [2-9]. $\mathrm{N}_{0}$ specific hiological role has yet been determined for PABI. Proteosome. one of large multicatalylic proteinases is apparently involved in ubiquitin independent protein degradation. It may also he involved in other important functions, such as a stabilizing effect on mRNAs [10,11]. Proteosome, $7700 \mathrm{kDa}$ in size, is composed of multisubunits with a molecular mass of 22-.33 $\mathrm{kDa}$. These proteinases are constitutive components of cells and can be activated by polylysine, SDS. ATP or heparin. These proteinases. however, are not known to accumulate intracellularly 1.2 the presence of small proteınase inhibitors. Recently, an ATP activated, highmolecular-weight proteinase isolated from muscle was reported to be a cysteine proteinase $\boldsymbol{\alpha}_{1}$-macroglohulin complex [12] 


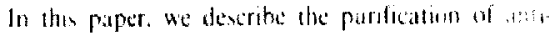
PABt orrsureasting matcrat from plasmit and

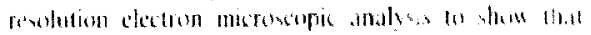

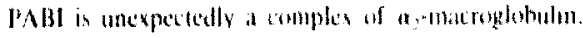

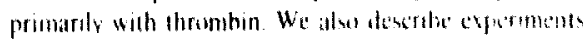

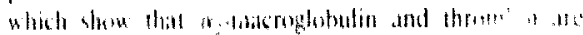

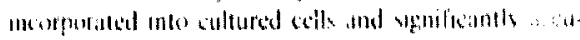
mulite in the prosence of leupepun.

\section{Materials and Methods}

\section{Moterials}

Purified human $a_{*}$-macroglobulin and iypsin $12 \times$ cryvalline) were purchased from Sigha (St. Lomis. MO). Purified hosine a $a_{2}$ materoglobulan was ohlaned from Beditinger-Mannheim (F.R.(i). Goat anti-rabhit IgCi conjugitud with alkitine phosphaliane and prestained SISS-PACit, standards (phosphorylase B, bovine serum alhumis, oxalbumin, carbonic anlyydrax, soybean itypin inhihitor and lyomyme) were from Bional laburalorics. Human thrombin (specific activity. 4.05 NIH units $/ \mu \mathrm{g}$ ) and anti-human prothrombin antibodies were kindly provided by Dr. Jules A. Shaler at the Department of Biochemistry of this campus. The thrombin preparation contained a-lhrombin as the major somponent besides its nicked darivatives $(\beta$ - and $\gamma$-lhrombin). Newborn call serum was from Whittaker Bioproducts (Walkersville, MD). 4-chloro-1-naphthol was purchased from Sigma. The other reagents used were of the highest analycical grade available.

\section{incparatum of andiscrum and immonoblot analysis}

Preparation of antiserum against purified PABI was previouly dexcrihed [1] Immunohlot analysis of proteims was calried ant as follows. Sodum dodecyl stilfate (SI)S) polyacrytumide gel electrophoresis (PACiE) was perfortited by the sacthod of lacmli [13]. The proteins sepafated were then stcersophoretically transferred to the nitrocellulose piper at a setting of $30 \mathrm{~V}$ for $16 \mathrm{~h}$ atcording to the nethod of Towbin et al. 1141. Immunodetection of PABI on nitrocellulose paper was carried sut as described previously [1]. Protein comcentration wat determined by the method of Bradford [15]. Double inmunodiffusion analyso was performed it rom temperature using 19 agarose in $50 \mathrm{mM}$ phosphate-bulfered saline (PBS) (pH 7.4), by the method of Ouchterlony [16]. After immumadiffusion, agarose gel was wawhed with PBS and then sained with Coomassic brilliant blue R-250.

\section{Purificatum of cross-reactang protein wih anti-PABl}

All purilication procedures were performed at $4^{\circ} \mathrm{C}$ unless oulherwise stated. Serum from newborn calf $(100$ aii) was incubated wih poly(ethyleneglycol) (PLC( $)$ (1010). The precipitate oblaned with $4.18 \%(\mathrm{w} / \mathrm{v}) \mathrm{Pl} G$ concentratum was dingelved with $25 \mathrm{mM}$ Tris-HCl (pH

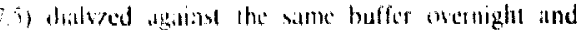

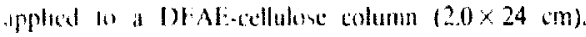

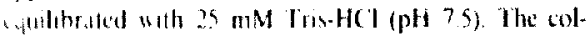
umm was toflemerely washed with the same huffer and cluted with 11 of a linear gradien buffer solution furmed of a iand $0.4 \mathrm{M} \mathrm{NaCl}$ all a flow rate of $60 \mathrm{ml} / \mathrm{h}$. fractions of $6 \mathrm{ml}$ were collected adel were andyed by immunublat analysis, Fractions contuining immunoreactivily werc pouled, concentrated by ultratcentrifugation $(18700 \times g, 20 \mathrm{~h}$ in a Beckman centrifuge) and the pellet was dissolved in $25 \mathrm{mM}$ Tris-HCl (pH 7.5) and applied to a hydroxy apatite column $(2.0 \times 18 \mathrm{~cm})$ equilibrated with $25 \mathrm{mM}$ Tris- $\mathrm{HCl}(\mathrm{pH} 7.5)$. The colunin was extensivaly wastied with the same huffer and etuted with a linear gradient of 0 to $0.3 \mathrm{M}$ sodium phosphate ( $\mathrm{pH} 7.4$. The monumoreative frations were cuncentrated by ultrafiltration (Amicon. XM.I00 tilter) and applied to a Sepharcryl \$-300) (superfine) column $(2.0 \times 9.3 \mathrm{~cm})$ equilihrated with $25 \mathrm{mM}$ Tris-Hil $\mathrm{chH}$ 7.5) coutuining $0.15 \mathrm{M} \mathrm{NaCl}$. The column was eluted with the same huffer at a flow rate of $15 \mathrm{ml} / \mathrm{h}$. Fractions of $2.0 \mathrm{ml}$ were collected and the immunoreastive fractions were pooled and concentrated by ultrafittaliim.

\section{Cell culture}

BHK cells were cultured in Eagle's minimum essential media (MEM) (Gibco) supplemented with streptomycin, penicillin and $10 \%$ felal calf serum in a $5 \% \mathrm{CO}$ incubatur al $37^{\circ} \mathrm{C}$.

\section{Imunumblot anuthsis}

Immunothlot analysis was carried out as previously described [1] with minor modifications. Cell extracts (7.5 $\mu \mathrm{g}$ as protein). media (7.5 $\mu \mathrm{g}$ as protein) or purified human $\alpha$-thrombin $(2.5 \mu \mathrm{g})$ nere dissolved in gel loading buffer $6.2 .5 \mathrm{mM}$ Tris- $\mathrm{HCl}$ (pH 6.8 , containing $10 \%$ glycerol. $2 \%$ SDS and $10 \%$-mercaptoshunol) and heated at $100^{\circ} \mathrm{C}$ for $5 \mathrm{~min}$. The samples were then subjected to SDS-polyacrylamide gel $(12 \%)$ electrophoresis employing a mini-gel appalatus (Bio-Rid). Prestained protein standards were used as size markers. The clectrophoresed proteins wert transferred to a nitrocellulose filter [14]. The blotted filters were incubated with $3 \%$ gelatin in $50 \mathrm{mM}$ Tris-HCl (pH 7.5) containing $0.15 \mathrm{M} \mathrm{NaCl}$ (TBS) at $37^{\circ} \mathrm{C}$ for $30 \mathrm{~min}$. The lilters were then incubated with the anti-PABI antiserum [1] at 1: 500 dilution. followed by incubation with goat anti-rabbil $\operatorname{la}_{\mathrm{a}} \mathrm{C}$ conjugated with horseradish peroxidase according to manufacturer's instructions. The filter hlottes with human thrombin was incubated with partially purified rabbit antibodies, anti-PABl antibodies or ribbit anti-human prothromhin antibodies at a $1: 1000$ dilution, following the procedures described above. The fitters were then incubated with TBS containing 4-chloro-1-napthol $(0.5 \mathrm{mg} / \mathrm{ab})$ for $30 \mathrm{~min}$ at 
room temperaturc. The anti-human prothrombin enpioved in the experinemts cross-r actod wh howins prollorombin.

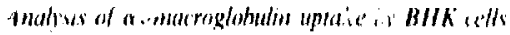

PABI depleted scrum was prepired as follows. Fetal call serum $2.5 \mathrm{ml}$ was added wilh a half volume of anti-PABI serum and incubated at $37^{\circ} \mathrm{O}$ Fo $;$. followed by continued incubation at $4^{\circ} \mathrm{C}$ overnight. The serum was then centrifuged at $3500 \mathrm{rmm}$ for $15 \mathrm{~min}$. I he supernatant oblained was used as $\alpha_{2}$-macroglobulindepleted FCS. BHK cells grown to near confluency in $10 \mathrm{~cm}$ dishes were briefly treated with $2 \mathrm{ml}$ of $0.25 \%$ (v, w) trypsin in $10 \mathrm{mM}$ sodium phorhale/salinc buffer (pll 7.4) (PBS buffer) containing $0.5 \mathrm{mM}$ EDTA. After discarding the :rypsin wolution, fresh PBS huffer (2 ml) was idied to harvest the cells. BHK cells were plated in $6 \mathrm{~cm}$ dishes at ahout $15 \%$ conlluency in cultured in 3.0 nI MEM with and without $60 \mu \mathrm{g} / \mathrm{ml}$ leupeptin, supplimented either with (1) 10\% FCS only, 2) 10\% PABl-dcpleted FCS or (3) 10\% PABI-depleted FCS containing $0.75 \mathrm{mg}$ hovine $\alpha_{2}$-macroglobulin. Cells were grown for $48 \mathrm{~h}$ to ahout $80 \%$ confluency and harvested by scraping after washing cells three times with 10 in M sodium phosphate saine $(\mathrm{pH}$ 7.4). The harvested cells were briefly centrifugeo and stored as a pellet at $20^{\circ} \mathrm{C}$ until use. In a separate experiment. BHK cells were grown for $48 \mathrm{~h}$ in media with and without leupeptin supplemented with, (1) 10\% PABI-depleted FCS preincubated with $0.75 \mathrm{mg} \alpha_{2}$-macroglobulin for $30 \mathrm{~min}$ al room temperature or (2) $10 \%$ PABI-depleted FCS preincubated with $0.75 \mathrm{mg} \alpha_{2}$-macroglobulin and $0.09 \mathrm{mg}$ thrombin for $30 \mathrm{~min}$ at room temperature.

For inmunohlot analysis, the frozen pellets were thawed and vigorously mixed by vortexing with $0.2 \mathrm{ml}$ of ice-cold $20 \mathrm{mM}$ Tris-HCl (pH 7.5 ) containing $1 \mathrm{mM}$ $\mathrm{CaCl}_{2}$. The homogenate was then centrifuged at $1200 \mathrm{H}$ rpm for 2 min and the supernatants obtained were tised as cell extract for Western blot analysis. An aliquon (15 $\mu$ ) of media diluted with the loading buffer to give the final protein concentration of $0.5 \mu \mathrm{g} / \mathrm{ml}$ was also suhjected to Western blot analysis.

\section{Electron mis rowopic analysis of PABI}

Sample preparation. A frozen stock solution of PABI $\left(75 \mu \mathrm{g} / \mathrm{ml}\right.$ in $25 \mathrm{mM}$ Tris and $5 \mathrm{mM}\left(\mathrm{aCl}_{2}\right)$ was thawed and $|\mu|$ was diluted in $50 \mu \mid$ of tricthanolamine buffer $(25 \mathrm{mM}$ triet hanolamine, $5 \mathrm{mM} \mathrm{CaCl}$, and $0.02 \%$ NaAzide) and fixe 1 for $1 \mathrm{~h}$ on ice with $1 \%$ glutaraldehyde. A drop of the fixed PABI solution $(3 \mu \mathrm{l})$ was applied to a glow discharged thin carbon film supported in i 'holey' carbon-coated EM grid. The sumpic was allowed to adsorb for 1 min, washed everal times with glass distilled water, stained with lo uranyl actitc. blolted and allowed to air dry.

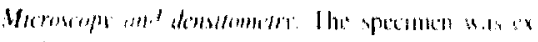

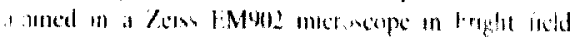

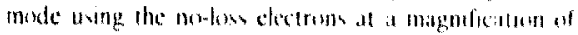

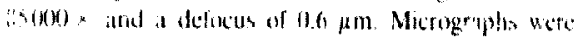
digitwod using a l'howometrics Stat I camera system with a Micro Nikkor $f: 55 \mathrm{~mm}$ lens 10 produce al find pixel size of $0.52 \mathrm{~nm}$. Imiges were transferred from a Nurthgate 386PC compatible computer to a VAXstalion $: 500$.

Imake analyis. Images of PABI were interactively selected on the VAXstation using the SPIDER whitwate syilem [17]. A reference parlicle was selecked and cen'es by angulat and transation corrctation with a low pass filtered image of a rectangle. Oher particles were restionally aligned with the low-pass liliered referene parlicle using the autocorrdaticn funcuon. Translational aligroment wats done hy cross-correlation A serne of similar lookng aligned parlicles wis awer. aged lo form a now refierene: which was lesed in al second alignment pats. Correspondence analysis [16] was performed on the aligned images to welect a subset to participate in the final average. The similar images were divided into two subaverages and a phase residual calculatior on their Fourier transforms provided information on the resolution $(3.3 \mathrm{mn}$ ) of the final average image [19].

Results

Purificatiun and adentificatom of amm-PABl cross-redetims material from basine plasma

As shown in Fig. I (left panel), anti-PABI antihedy [1] stromgly cross-reacted with calf plasma and weakls. but clearly. with human plasma. It did not cross-reist with rat plasma. Immunohlot analysis showed a band al molcular weighe of absut logoog for both calf planmit and inumar plasma with much higher butersity for call

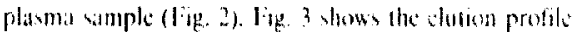
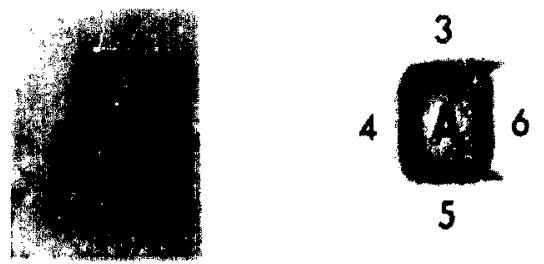

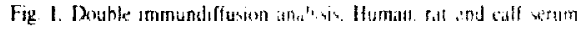

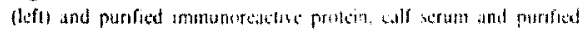

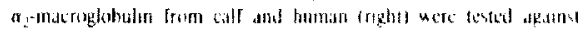

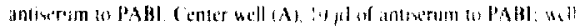

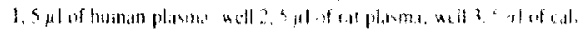

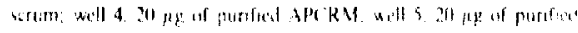

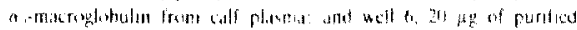

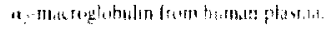


with three peaks from sephacryl S-300 with immunoblot analysis of elution fractions. The front peak which contains the major band of at out 180000 was observed as cross-reacting material. A ew minor bands $u_{z}$ lower molecular weights were also observed. The anti-PABI cross-reactivity material (ADCRM) was purified to more than $95 \%$ homogeneity (Fig. 4). About $60 \ldots$ of the puritied APCRM was abtained from $100 \mathrm{ml}$ of newhorn calf serum. The yield was estimated to be about $30 \%$. The purified APCRM was then tested for its identity with plasma $\alpha_{2}$-macroglobulin. Cross-reactivity of antiPABI with purified bovine $\alpha_{2}$-macroglobulin is shown in Fig. 1 (right panel). The precipitine line clearly fused vith that of purified APCRM (wells 4 and 5) strongly suggesting the identity of APCRM with bovine $\alpha_{2^{-}}$ macioglobulin. The precipitine line of purified human $\alpha_{2}$ macroglobulin fused neither with that of purified bovine $\alpha_{2}$-macroglobulin nor with that of APCRM in calf plasma. When the purified APCRM and the purified bovine $\alpha_{2}$-macroglobulin were digested with trypsin. essentially identical fragmented peptide patterns were observed (Fig. 4). These results indicate that the major component of PABI is bovine $\alpha_{2}$-macroglobulin.

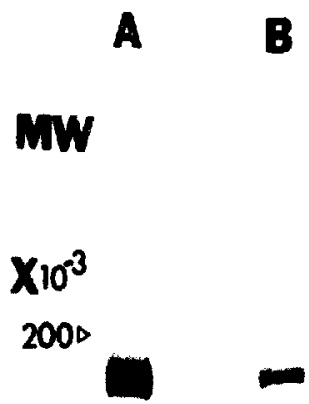

$97 \triangleright$

670

Fig. 2. Immunoblot analysis of PABI in calf serum and human plasma. $1 \mu \mathrm{l}$ of plasma added with $4 \mu \mathrm{l}$ of the loading buffer was treated in boiling watet for $5 \mathrm{~min}$ before application to the SDS-polyacrylamide gel (4-15\% gradient gel). Protein hands separated were visualized by immunostaining with anti-PABI serum. Lane A, calf serum: and lane B, human serum.

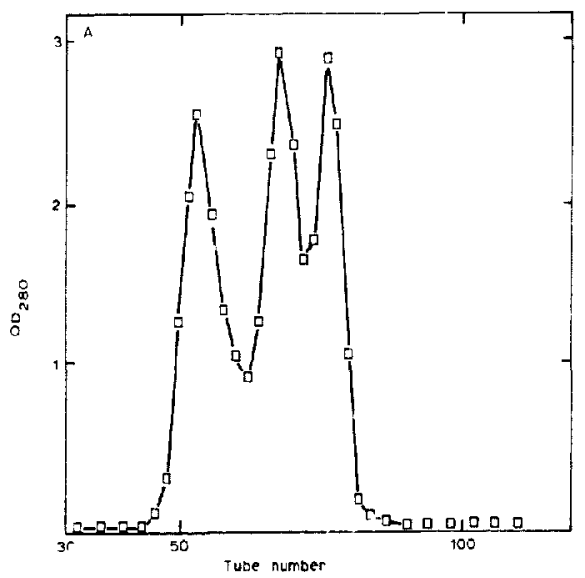

B

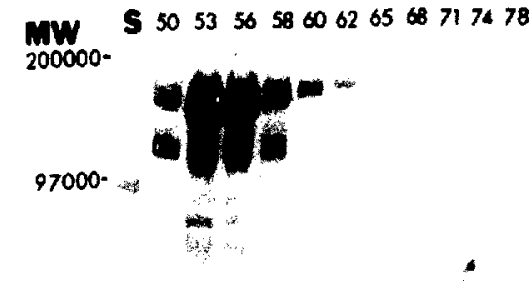

Fig. 3. Gel filtration of the immunoreactive protein with antiserum against PABI on Sephacryl S-300. The cluate from hydroxy apatite were applied to the column $(2 \times 93 \mathrm{~cm})$. The column was then eluted at a flow rate of $15 \mathrm{ml} / \mathrm{h}$ with $25 \mathrm{mM}$ Tris-HCl $(\mathrm{pH} 7.5)$ containing $0.15 \mathrm{M} \mathrm{NaCl} .5, \mathrm{l}$ of fractions were applied to SDS-polyacrylamide gel 14-15\% gradient gel) and immunoblot analysis was carried out. (A) protein elution profile; (B) immunoblot analysis with anti-PABI serum.

but not other proteins such as $\alpha_{1}$-macrog'obulin and pregnancy zone protein.

\section{Electron microscopic analysis of $P A B I$}

Results of electron microscopic analysis and computer image analysis are shown in Fig. 5. Panel A shows the electron microscopic image (side view) of PABI. Computer image analysis revealed the $\mathbf{H}$ shaped structure of PABI. This structure was found to be highly similar to the basic model determined for tetrameric human $\alpha_{2}$-macroglobulin complexed with either chymotrypsin, trypsin or thrombin which was described as a padlock shape, $H$ shape or cyrillic character shape [2023]. The ninety degree rotated image (end view) was also very similar to that of human $a_{2}$-macroglobulinchymotrypsin complex previously reported [22]. Because the shape of the $a_{2}$-macroglobulin molecule is unique, 


$M W \times 10^{-3}$

Fig. 4. SDS-polyacrylamide gel electrophoresis of the purified immunoreactive protein, a.-macroglobulin and their tryplic pepides. Polyacrylamide gel employed was for a linear gradient get formed of 4-15\%. Purified a -macroglohulin from cull plasma, hafore (lane 1) and after (lane 3) digestion with trypsin (molas ration $1: 1$ at $37^{\circ} \mathrm{C}$ for $1 \mathrm{~h}$ ) and the immuno reactive proteins (APCRM) before (lane 2) and after (lane 4) digestion with trypsin (molar ration 1:1). Proteins were detected by silver staining.

these observations strongly suggest that PABI is identical to a complex of tetrameric $\alpha_{2}$-macroglobulin and a proteinase(s).

\section{Immunoblot analssis of $P A B I$}

The results of immunoblot analysis of human thrombir ith anti-PABI antibody as well as anti-prothrombin antibody are shown in Fig. 6. In this immunoblot analysis, both anti-PABI and anti-prothrombin detected the B-chain of human $\alpha-$ thrombin ( $33 \mathrm{kDa}$ band in this gel) and its nicked derivatives (bands $c$ : about 13,22 and $19 \mathrm{kDa}$ ) [24]. A-chain of $\alpha$-thrombin (62 amino acid residues in lengih) ran out of the gel and is not shown in this picture. These results strongly suggest that at least one type of the proteinases complexed with $a_{2}$-macroglobulin in PABI is thrombin. Antiplasmin failed to cross-react with PABI (data not shown), agreeing with the previous observation that PAB! does not have plasmin-like substrate specificity [1]. Other proteinases with chymotrypsin-like substrate specificity which may also be complexed wilh on-matroglobulin have yet to be identified.

$a_{2}-$ matcroglohulin uptake $h_{\text {? }}$. PHF cells

Fig. 7 shows the presence and absence of $\alpha_{2}$-macroglobulin (bands $a$ and $b$ ) in the culture media of BHK cells under various conditions. When the intact serum was supplemented to the media. the presence or absence of leupeptin did not make any apparent difference on
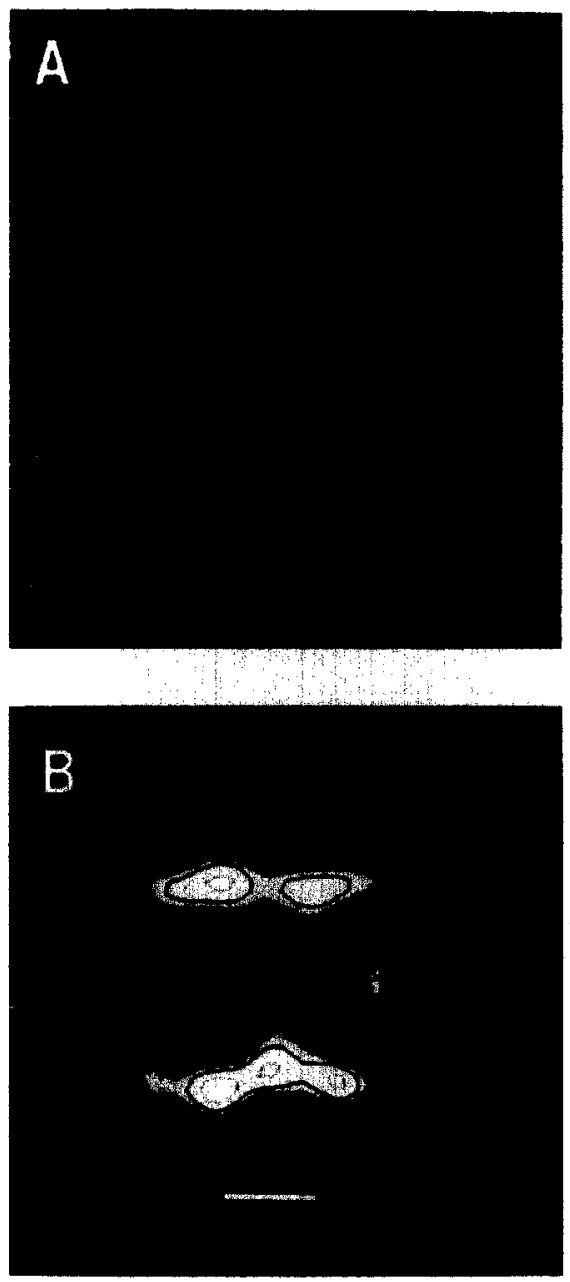

Fig 5. Electron Microscopic analysis of PABl. (A) Electron micrograph of PABI macromolecules negatively stained with uranyl acetate and imaged in bright field. no energy-loss mode with a Zeiss EM902 microscope. PABI hate the $\mathrm{H}$-like structure characteristic of amacroglobulin complexed with proteinase. Magnification: $248000 \mathrm{x}$. (B) Average of aligned PABI mages after low-pass filtration wo 3.3 $\mathrm{nm}$ resolusion Contour lines delineate regions of similar stain excla. sion. Scalc bar is $10 \mathrm{~nm}$. 


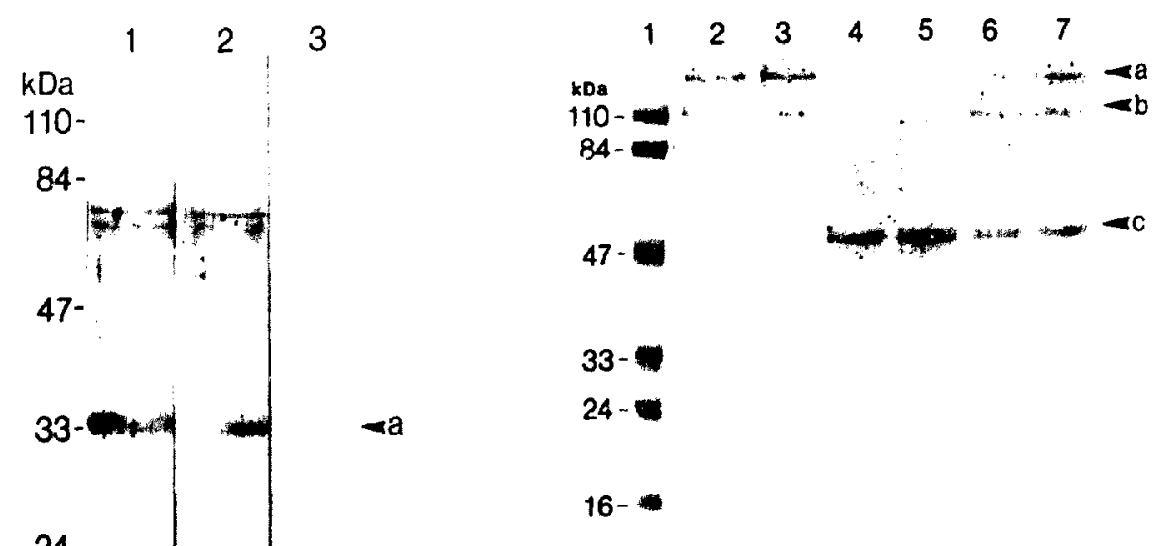

Fig. 6. Immunoblot analysis of thrombin with anti-prothrombin and ant.PABI antihodiew. Human thrombin simples were electroptorexed ill a 12 , polyacrylamide gel in a reduced condition, and hloted to a filter as deverihed in the text. All lanes contain $2.5 \mu \mathrm{g}$ or a-dhrombir. Lune' 1. stainted with anti-thrombin antibody as the first antibody: lane 2. stained wath anti-PABI antibod:: and lane 3, stained with

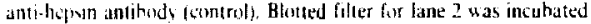
longer for collor develupment (15 min) than for the filter of tane 1 (10 min) to clearly show the stained bands. Sizes (KDa) of the protein vandards are shown on the left. Band a corresponds to B-chain of a-thrumbin. while band $b . c$ and $d$ correspond in derivatives of nicked $\mathrm{H}$-chain in the thrombin preparation.

the a-macroglobulin concentration in the media llanes 1 and 2). $\alpha_{2}$ - Macroglobulin-depleted serum showed only a trace amount of $\alpha_{2}$-macroglobulin in the media (lanes 4 and 5 of Fig. 7). white the media supplemented with purificd hovine $\alpha_{2}$-macroglobulin again shows $\alpha_{2}$ macroglobulin bands (lanes $f$ and 7$)$ as intense as in lanes 1 and 2 . These results indicate that the amount of anti-PABI antibodies employed to deplete serum $\alpha_{2^{-}}$ macroglobulin is just enough to deplete the endogenous serum $\alpha_{2}$-macroglobulin. and not in excess to further hind the supplemented purified $\alpha_{z}$-macroglobulin. Band $C$ in lanew 4. 5.6 and 7 in Fig. 7 correspond to a fragment derived from rabbit anti-PABI IgGs added to the media in order to deplete serum $\alpha_{2}$-macroglob. 'in.

When intraceltular PABI wis analyzed (Fig. 8), much more elevated $\alpha_{2}$-macroglobulin levels (represented by bands $a . b$ and $c$ of lanes 3 and 7 in Fig. 8) were

Fig. 7. Immunoblot analysis of BHK cell culture media with anti-PABI antibodien. Protein samples were alectrophoresed in a $12 \%$ polyacryl. amide get in a reduced condition. blotted to a filter and analyzed with anti-PABI antihodies as described in the text. Sizes ( $k D_{a}$ ) of the prestained standard proteins (Lane 1) are shown on the leit. Lanes 2.7 cuntain $7.5 \mu \mathrm{g}$ of BHK proteins Lanes 2 and 3 contain proteins from cells stown in media supplemented with $10^{\circ}$ calf fetal serum: lanes 4 and 5 contain proteins from cell grown in media supplemenled with $10 \%$ PABI-depleted serum: banes 6 and 7 contain proteins from cells gown in media supplemented with $10 \%$ PABt-depleted serum and purified bovine $\alpha_{2}$-macroglobulin final 0.25 ing/ml). (ulture media for cells in lanes 3.5 and 7 was supplemented with leupeptin. Bands shown with arrows a and b cortespond to $a_{2}$-mucroglibulin. Band $s$ corresponds lo fragment derived from reduced rahbit lghs stained with goat anti-rabbit IgGi.

observed in the presence of leupeptin compired to those in the absence of leupeptin (lanes 2 and 6). In the absence of leupeptin. apparent intracellular degradation products of $\alpha_{2}$-macroglobulin (band e) were observed at

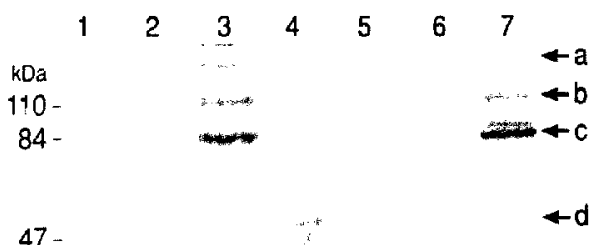

$33-$

$24-$

$16-$

Fig. X. Immunoblot andlyss of BHK cell extracts with anti-PAB! antibodiex. Proteins of the cells were analyzed with anti-PABl antihodies. All wher experimental conditions and numbering are same as in Fig. 7. Bandi a. b. c. d and e correspond to the fragments derived frem at:macroplubulin. 


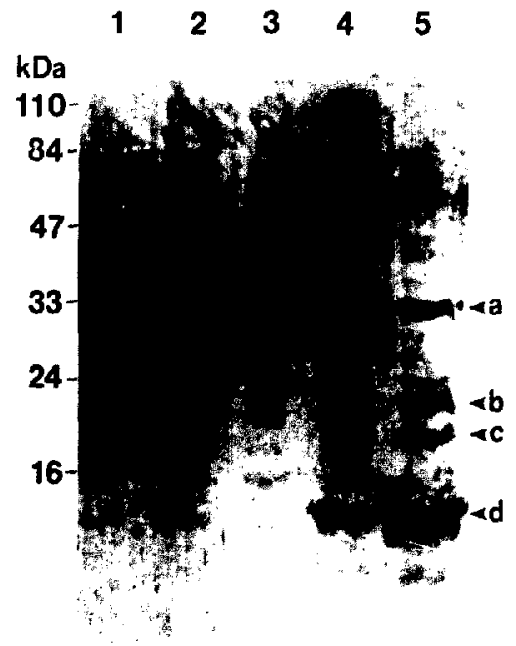

Fig. 9. Immunoblot analysis of BHK tell exlracts with anti-prothrombin antibodies. Protein samples were electrophoresed in $112^{\circ}$; polyacrylamide gel in a reduced condition. The bloted filter sere then incuhated with anti-prothrombin antibodies. Lanes 1 and 2 contain proteins $(7.5 \mu \mathrm{g})$ from cells grown in media supplemented with 109 PABl-depleted serum added with $\alpha$-macroglobulin without and with leupeptin, respectively: lanes 3 and 4 conlsin proteins 17.5 $\mu \mathrm{g}$ f from cells grown in media supplemented with $10 \%$ PABI-depleted serum added with a-mactoglobulin and thrombin withoul and with leupeplin. respectively; lane 5 contains $2.5 \mu \mathrm{g}$ of $\alpha$-thrombin. Band a corresponds to B-chain of o-thrombin. while hands $b . c$ and $d$ correxpend to nicked derivative of R-chain inet Fig. 6)

much higher levels (lanes 2.4 and 6 in Fig. 8) compared to the trace amount of band $e$. if any. in the presence of leupeptin (lane 3 and 7). Band d was also considered to be an intracellular degradation product of PABI. These results show that bovine $\alpha_{2}$-macroglobulin in the media is internalized by BHK cells followed by efficient intracellular degradation in the absence of leupeptin. but significant protection from degradation in the presence of leupeptin resulting in its great accumulation in cells.

As shown in Fig. 9, anti-prothromibin antibodies recognized greatly increased intracellular thrombin in the presence of leupeptin (bands a and $d$ in lane 4). only when both $\alpha_{z}$-macroglobulin and thrombin were auti.t to the PABI-depleted calf serum. The increase was not observed when the serum was supplemented only with $\alpha_{2}$-macroglobulin. These results indicate that the formation of the complex (PABI) between $\alpha_{2}$-macroglobulin and thrombin is a prerequisite for internalization and subsequent intracellular accumulation of PABI in the presence of leupeptin ( $\mathrm{Fig}$. 9). The results also suggests that free and active thrombin is essentially absent in the PABI-depleted serum (lane 2 of Fig. 9). Thrombin in serum might have been consumed not only by forming
PABI complex and complexes with onter protcinase inhibitors such as antithromhir? III. hut alse by degradations. When ant:-PABI antibodiss were used in place of anti-prothrombin in this experiment. an increased amount of intracellular $\mathrm{PABI}$. and its protection from degradation in the presence of leupeptin were observed as expected idata not shounl.

These results show that at least one of the proleinases complexed with a -macroglohulin in PABI in thrombin in the serum which is added to the culture media.

\section{Discussion}

PARI was originally identified as a large. multistalytic proteinase that is greatly elesated in its intracellular concentration primarily in the lysonomal fraction in the presence of small proteinase inhibitors, such as !eupeptin [1]. In order to determine its biological role. PABI was further characterized in the present study.

We first carricd out electron microscopic analysis of PABI to compare with the tertiary structures previously reported for other large proteinases [25]. The electron microscopic image obtained for PABl was unexpectedly very similar to those of tetrameric $\alpha_{2}$-macroglobulin complexed with proteinases, such as chymotrypsin and trypsin (Fig. 5) [21-23]. The result strongly suggested that PABI was a complex of $\alpha_{-}$-macroglohu'in and a proteinase(5). which was internalized by the cultured celis. presumably by the receptor wediated endosytosis $[26-28]$. The result also provides further evidence thit the $\boldsymbol{H}$ shaped electron microscopic image is of the $\alpha_{2}$-macroglobulin complexed with a proteinase(s). but not $o$ the native form of $\alpha_{2}$-macroglobulin as previously postulated [29].

Tests for immunological crow-reacivity (Figs. I and 2) show that anti-PABl cross-reacting material (APCRM) is also present in sera. and that APCRM forms fused precipitine lines onis with bovine $\alpha_{2}$ macroglohulin. Furthermore ather properties of the purified APCRM. such as tryptic peptide map also agree well with those of $\alpha$-masroglobulin. These results searly indicate that the major component of PABI in serum a -macroglobulin and not other proteins inciud. ing its homolngous proteins. such is $\alpha_{1}$-macroglobulin or pregnancy zone protein [12.30].

The proieinases complexed with $\alpha_{2}$-macroglobulin in PABI include those which have trypsin-like or chymotrypsin-like specificty. but neither cysteine proteinase. distase nor plasmin-like proteinases as previously observed [1]. This suggests that intracellular proteinases iparticularly lysosomal proteinases) produced by the cells are appartntly not complexed with $\alpha_{2}$-macrogiobulin in PABI. These observations ant consistent with the well established fact that the cell receptor 
abonition ste of $\alpha_{2}$-matrogiabulin molecule becomes availatle only after $\alpha_{2}$-microglohulin undergoes a subsuritai conforitiatonal changes upon forming a com plex with a proteinate (s) (F" a.M M $\{21.27 .28 .31\}$.

Becalke sothetic suthetrates such as CBZ-Arg-MCA. Z-Ph-Arg-MCA and BCr-Val-Ieu-Ly-MCA were vert poor substralcs for PALI |1]. the proteinase in PABI was considered not to be trypsin. The majotrypsin-like substrate specificity of PABi. however. Was rather similar to that of thrombin [1]. Therefore. we speculated that thrombin is a possible proteinase component of PABI. In immunoblot analysis, both anti-prothrombin antibody and anti-PABI antibody recognized $\alpha$-thrombin and its derivatives by staining identical bands in Western blot analysis (Fig. 6). This indicates that thrombin present in the supplemented serum is one of the major proteinases complexed with $\alpha_{2}$-macroglobulin in PABI. Results of a series of PABI uptakc experiments (Figs. 7-9) clearly show that leupeptin. transported to the lysosomes of the cells [1]. protected PABl molecules from proteolytic degradation. resulting in high accumulations of PABI in the cells. Furthermore. the results of $\mathrm{PABI}$-depletion and protein supplemontation experiments (Fig. 9) show that thrombin complexed with $\alpha_{2}$-macroglobulin can be taken up by cells, agreeing well with the previous observations [2628]. A proteinase(s) with chymotrypsin-like suhsirate specificity is also contained in some PABI molecules [1]. The intrinsic chymotrypsin-like activity of thrombin may be responsible for this activity [35-38]. At the present, however. no definitive identity of the proteinasc(s) is avalable. Major proteinases which are complexed with $\alpha_{2}$-macroglohulin in PABI are apparently restricted to a few proteinases. such as thrombin, probably due to their availability as active proteinases in serum. This may further suggest that the intracellular ascumulation of PABl observed in the present experiments is a phenomenon anly relevant to the cultured cells which are exposed to the media containing $\alpha_{2}$ macroglobulin complexed with activated proteinases such as thrombin.

We have also observed that cultured rat capillary enduthelial cells can elevate their PABI concentration to a very high level in the presence of leupeptin (unpublished data). These results may further suggest that $\alpha_{2}$-macroglobulin apparently functions as an internalizalion vehicle for thrombin and some other specific proteinases in the plasma not only for the clearance of those proteinases from the plasma, but also for bringing those proteinases to their potential, alternative function site in cells. Recently. $\alpha_{2}$-macroglobulin hindings were reported for interleukin-1 $\beta$ [39]. basic fibroblast growth factor [40] as well as for transforming growth factors $[41,42]$. These observations further suggest an important function of $\alpha_{z}$-macroglobulin as a general carrier protein for heterologous, but specific proteins in the plasma.
Osada et al. [43.44] reported the use of $\alpha_{2}$-macroglobulin-proteinase complex as a carrier vehicle to transport a-galactosidase into the cells. This approach is of a greal importance in considering a possible enzyme replacement hicranv for lysosomal enzyme deciciencies. such as Tabry'، cisease [4.3]. Small proteinase inhibitors may serve to augment the effect of such therapies by enriching the $\alpha$,-macroglobulin complex in the cells.

Tanaka et al. [45] previously reported isolation of an acidic thiol proteinase induced in rat liver by the intraperitoneally administered leupeptin. Interestingly. when leupeptin was injected into peritoneal cavity of rats in our preliminary study, a significant incrcase in the intensity of an immunostained band of about $90 \mathrm{kDa}$. whici corresponds to PABI. was observed in the liver as well as in the kidney (unpublished data). This observation suggests a significant accumulation of PABl in vivo may also take place when leupeptin is given to the animals. The proteinase(s) component of the PABI in vivo is to be determined. The observations made in the presen, study are also important for better understanding of the in vivo mechanism of action of small peptide proteinase inhibitors which are given to patients for muscle dystrophy treatment or in other pathological conditions $[46-48]$.

\section{Acknowledgement}

This work was supported in part by NIH (research grant HL38644 to K.K.

\section{References}

I Tsuji. A und Kurachi, K. (1989) J. Biol. Chem. 264, 16093-16099.

2 Rone. I., Watrm, J.V.B and Hershka. A. (1979) J. Biat. Chem. 254. $8135-8138$

3 Tanika, K. li. K.. Khihara. A. Waxman. L. and Goldberg. A.L. (1986) 3. Buol. Chem. 261. 15197-15203.

4 Dahimann. B. Kuehn, L., Ruischmann. M. and Keinauder. H. (1985; Bixhem. J. 228.161-170)

5 Whiura. S. Sano. M. Kamakura. K. and Sugna. H (1\%5) FEBS Lett. 1 K9. $119-123$.

6 Rivett. A.J. (1985) J. Biol. (hem. 260. 126(k) 12606

7 Tanaka. K.. Yoshimute. T.. Ichihara. A.. Kameyama. K, and Takagi. T. (1986) J. Biol. Chem. 261, 15204-15207.

* Demartino. G.N and Goldherg. A.L. (1979) J. Biol. Chem. 254. $3712-3715$

9 Ray. K. and Harris. H. (1965) J. Biol. Chem. 82. 7545-7549.

10 Arrigo. A.P.. Tanaka. K.. Goldherg. A.L. and Welch. W.J. (1988) Vature 331. 192-194.

II Driscoll. J. and Goldherg, A.L. (1989) Prec. Natl. Acad. Sci. USA 86, 787-79]

12 Duhlmann. B., Kuehn. L., Heinrich. P.C.. Kirschke, H. and Wiederanders. B. (1989) Biochim. Biophys Acta 991, 253-262.

1? Laemli. L.K. (1970) Nature 227,680-685.

14 Toubin. H., Stuehelin. T. and Gordon. J. (1979) Proc. Natl. Acad. Sci. USA. 76. 4350-4354.

15 Bradford. M.M. (1976) Anal. Biwhem. 72. 248.254

16 Ouchterlony, O. (1958) in Progress in Allergy (Kallos, P., ed.). Vol. \$. pp. $1-78$. Karger. Barsel 


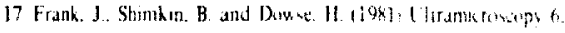
$343 \ldots .4 \mathrm{x}$.

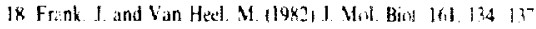

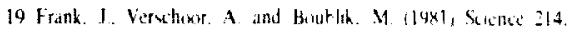
$1353-1355$

20 Tapon-Brequdiete. J. Brom. A. (outure-Ja, E and Delan. E. (!985) EMBO 3. 4. 85-89.

21 Delain. E.. Barray. M.. Tapon-Breaudiere. J.. Pochon. F. Maryen. P.. Cassiman. 1.J. Yan den Bierghe. H. and Vin Learen. F. (1986) J. Bir'. Chem. 263. 2981-2984;.

22 Bretaudiere, J.-P.. Tapon-Bretaudiert, J and Strops. I.K. 11448, Prox. Null Acad. Sui. USA 85, 1437 1441

23) Sjoherg. B. and Pap. S (1989) J Binl Chem. 264. 14686 1469)

24 Doyle. M.F and Wann. K ( 11940$)$ ]. Biol Chent. 265. 106931070!!.

25 Tanaka, K., Yoshimura. T., lchihara, A.. Ikal, A., Nishigai. M.. Morimoto. Y.. Sato, M. Tanaka, N., Kattube, Y. Kameyama, K. and Takagi. T. (1988) J. Mol. Biol. 2C3, 985-996

26 Sottrup-Jensen. J. (1987) in The Plasma Proteins (Putnam. F.W. ed.). 2nd Edn.. Vol. 5. pp. 191-291. Academic Press. Orlando.

27 Sottrup-Jensen. L. (1989) J. Biol. Chen. 264. 11539-11442.

28 Moestrup, SK and Gliemanu. J. 1989) J. Bios. Chem. 264. 15574-15577.

29 Feldman. S.R., Gonias. S.L. and Pizzo, SV. 1J985\} Prox Vatl Acad. Sci. LSA 82,57(0) $57(14$

30 Christens'n, U., Sumonsen. M., Har at. N. and Sottup-Henten. L. (1984) Biochemısin 28, 9.24-9331.

3) Gliemann. J.. Larsen. T.R. and Sotrup-Jer.,n. L. (19k7, Bikhim Biophys. Actid 776. 230-237.

32 Davidsen. O.. Christensen. F.I and Gtiemann. I (1485) Biwhim Biophyx. Acta 846,85-9?.

33 Feldman, S.R.. Rosenberg M.R. Ney, K.A. Michalopouter. G; and Pizzo. S.V. (1985) Biochem. Biophys. Res, Commun. 12k. $745-802$.

34 Spolarics. Z. Manull, J., Machovitk. R. Lambin. P.. Garzo. T.

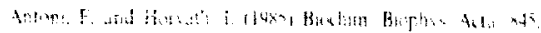
ing ilis

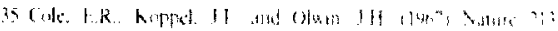
जाय Sulf

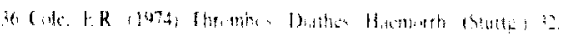
$12314 x$.

3 Rian. TJ. Fenton IW II Chang. I f ant lanmian. Ri) 11976 B Bubemaly $15.759-1341$

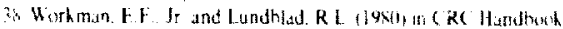

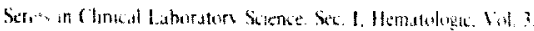

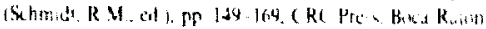

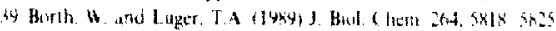

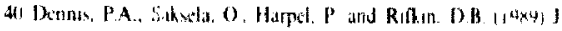
[bol. Chem. 2(44, 7?10 73).

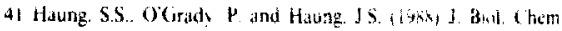
263. $1535-1541$

42 Danielpoure. D. and Sporn. MB. (1946i J. Butl. Chem. 365. $6973-6977$.

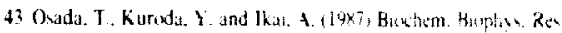
Commun 14?. 110 - loth

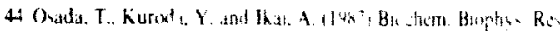
Commun. 142. 454.958 .

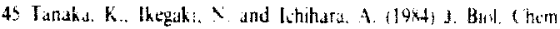
259. 59375444

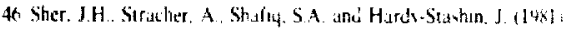

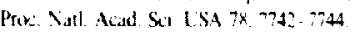

47 Hanida K. Tamal. M. Adach. T., Ojuma. K. Kathimal. K Ohm it. S. Kaminame. K. Timators. T. and Kilumums, $\$$

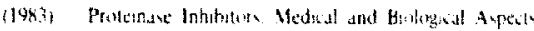

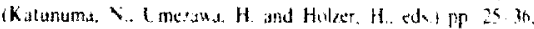
Japan. Sil. Son. Frew Spronger Ferlag. Berhon.

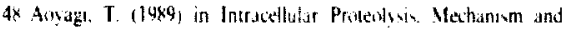

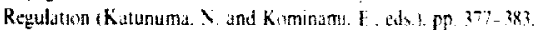
Japan. Si Sik Prems. Tohbo 